\title{
Retraction
}

\section{Retracted: Induction of Heat Shock Protein Expression in Cervical Epithelial Cells by Human Semen}

\author{
Infectious Diseases in Obstetrics and Gynecology \\ Received 29 October 2017; Accepted 29 October 2017; Published 13 November 2017 \\ Copyright (c) 2017 Infectious Diseases in Obstetrics and Gynecology. This is an open access article distributed under the Creative \\ Commons Attribution License, which permits unrestricted use, distribution, and reproduction in any medium, provided the \\ original work is properly cited.
}

Infectious Diseases in Obstetrics and Gynecology has retracted the article titled "Induction of Heat Shock Protein Expression in Cervical Epithelial Cells by Human Semen" [1]. The article was found to report the same results, without citation, as the following published article: J. Jeremias, S. S. David, M. Toth, S. S. Witkin, "Induction of messenger RNA for the $70 \mathrm{kDa}$ heat shock protein in HeLa cells and the human endocervix following exposure to semen: implications for antisperm antibody production and susceptibility to sexually transmitted infections," Human Reproduction (1997) 12 (9): 1915-1919. DOI: https://doi.org/10.1093/humrep/12.9.1915 [2]. The last author does not approve of retraction and the other authors could not be contacted.

\section{References}

[1] J. C. Jeremias, A. M. Bongiovanni, and S. S. Witkin, "Induction of heat shock protein expression in cervical epithelial cells by human semen," Infectious Diseases in Obstetrics and Gynecology, vol. 7, no. 1-2, pp. 17-22, 1999.

[2] J. Jeremias, S. S. David, M. Toth, and S. S. Witkin, "Induction of messenger RNA for the $70 \mathrm{kDa}$ heat shock protein in HeLa cells and the human endocervix following exposure to semen: implications for antisperm antibody production and susceptibility to sexually transmitted infections," Human Reproduction, vol. 12, no. 9, pp. 1915-1919, 1997. 
Induction of Heat Shock Protein Expression in Cervical Epithelial Cells by Human Semen

\author{
J.C. Jeremias,* A.M. Bongiovanni, and S.S. Witkin \\ Division of Immunology and Infectious Diseases, Department of Obstetrics and Gynecology, Weill \\ Medical College of Cornell University, New York, NY
}

\begin{abstract}
Objective: The 70kD heat shock protein (Hsp70), induced when cells are subjected to environmen-
\end{abstract} tal stress, prevents the denaturation and incorrect folding of polypeptides and may expedite replication and transmission of DNA and RNA viruses. We analyzed whether messenger RNA (mRNA) for Hsp70 was expressed following exposure of a cultured human cervical cell line (HeLa cells) to human semen or in cervical cells from sexually active women.

Study Design: HeLa cells were co-cultured with a 1:50 dilution of semen from four men or with purified spermatozoa or cell-free seminal fluid. Endocervical swabs were acquired at mid-cycle from 53 women. Heat shock protein $70 \mathrm{mRNA}$ was detected by a reverse transcriptase-polymerase chain reaction utilizing specific primer pairs and analysis on agarose gels. In cervical cells $\mathrm{Hsp} 70$ mRNA was measured identically followed by hybridization with an Hsp70-specific internal probe and detection by enzyme-linked immunosorbent assay (ELISA). Cervical immunoglobulin A (IgA) antibodies to the human Hsp70 were determined by ELISA.

Results: HeLa cell-semen co-culture resulted in the induction of Hsp70 mRNA. In addition, cell-free seminal plasma and motile sperm incubated individually with HeLa cells also induced this mRNA. Heat shock protein $70 \mathrm{mRNA}$ was detected in $28(52.8 \%)$ of 53 endocervical samples obtained from women at various time points following intercourse. The percentage of samples expressing this mRNA was $37.5 \%$ at less than 10 hours, $64.3 \%$ at 10 hours, $70 \%$ at 11 hours, and between $36 \%$ and $50 \%$ at later times after semen exposure. The detection of cervical IgA antibodies to the Hsp70 was highly associated with Hsp70 gene transcription.

Conclusion: Human semen induces transcription of Hsp70 in cervical epithelial cells. Infect. Dis. Obstet. Gynecol. 7:17-22, 1999. 우 1999 Wiley-Liss, Inc.

\begin{tabular}{c} 
KEY WORDS \\
semen; human; heat shock proteins; cervical cells; Hsp70 \\
\hline
\end{tabular}

$\mathrm{H}_{\mathrm{s}}^{\mathrm{cos}}$ eat shock proteins (Hsps) are universal constituents of all prokaryotic and eukaryotic cells. Constitutively synthesized Hsps function as molecular chaperones, aid in antigen presentation, and regulate steroid receptor function. ${ }^{1} \mathrm{Hsps}$ may also be induced following exposure to a wide variety of physio-chemical insults: temperature variation, steroids, amino acid analogues, heavy metals, and oxidative damage. ${ }^{2}$ Mammalian cells produce
Hsps in response to infection by viral or bacterial pathogens, and this response has been indicated to exert a cytoprotective effect during disease pathogenesis. A number of investigators have demonstrated that induction of transcription of the gene coding for the inducible heat shock protein 70 (Hsp70) led to an inhibition of transcription of genes coding for the pro-inflammatory cytokines interleukin- 1 and tumor necrosis factor- $\alpha{ }^{3-6}$ Tran-

*Correspondence to: Jan C. Jeremias MSc, Department of Obstetrics and Gynecology, Weill Medical College of Cornell University, 515 East 71st Street, New York, NY 10021. E-mail: jaj2003@mail.med.cornell.edu 
scriptional induction of Hsps requires activation of a heat shock factor, a transregulatory protein that attaches to specific promoter elements located upstream of several Hsp genes.

Seminal fluid is rich in prostaglandins, polyamines, zinc, proteases, and other enzymes, which may initiate a stress response and thereby induce transcription of Hsp70 in endocervical cells. Contact between sperm and endocervical cells may also bring about a stress response. Spermatozoa are capable of associating with, and even penetrating into, somatic cells. ${ }^{7}$ During coitus, the $\mathrm{pH}$ in the vagina changes from 4.0-4.5 to approximately 7.0. Since an acidic $\mathrm{pH}$ suppresses the synthesis of Hsp $70,{ }^{8}$ neutralization of the $\mathrm{pH}$ in the vagina by semen would create a milieu, at this site, acceptable for the synthesis of Hsp70. Therefore, it was of interest to determine whether semen induced Hsp70 messenger RNA (mRNA) in cells of the female genital tract. The actuality of such induction would suggest an additional mechanism limiting immunity to spermatozoa: prevention of proinflammatory cytokine synthesis and T-lymphocyte activation secondary to initiation of $\mathrm{Hsp} 70$ gene transcription. In this communication we demonstrate that human semen, as well as cell-free seminal fluid and motile spermatozoa, induced Hsp70 mRNA transcription in a cell line derived from human cervical cells. The Hsp70 mRNA was also identified in cells of the endocervix from sexually active women after intercourse.

\section{MATERIALS AND METHODS

$$
\text { Cell Culture }
$$

Human cervical (HeLa) cells, obtained from American Type Culture Collection (ATCC, Rockville, MD), were cultured in Dulbecco's modified Eagle's medium supplemented with $10 \%$ fetal bovine serum, $1 \% \mathrm{~L}$-glutamine, and $0.05 \mu \mathrm{g} / \mathrm{mL}$ gentamicin. Cells were maintained in a $37^{\circ} \mathrm{C}, 5 \% \mathrm{CO}_{2} /$ 95\% air atmosphere.

\section{Processing of Semen}

Semen samples were obtained by masturbation. Following liquefaction, motile spermatozoa were isolated by overlaying the semen samples with an equal volume of sterile warm $\left(37^{\circ} \mathrm{C}\right)$ phosphate buffered saline (PBS), incubated at $37^{\circ} \mathrm{C}$ for 60 minutes, and collecting the upper PBS layer. The remaining semen was centrifuged, and cell-free seminal fluid was sterilized with a $0.2 \mu \mathrm{m}$ syringe filter.

\section{HeLa/Semen Experiments}

Cells were grown in 24 well flat bottom plates until confluent, after which the monolayers were washed with Hank's Balanced Salt Solution (HBSS). Unfractionated semen, seminal fluid, or motile sperm, diluted as indicated in the individual experiments, was added to each well in duplicate. After an overnight incubation in a $37^{\circ} \mathrm{C}, 5 \% \mathrm{CO}_{2}$ incubator, 0.5 $\mathrm{mL}$ of $0.25 \%$ Trypsin- $1 \mathrm{mM}$ edetic acid (EDTA) was added to each culture and like wells were pooled and washed twice with HBSS. The collected cells were pelleted by centrifugation at 6500 rpm and RNA extracted as described below. Viability was determined on an aliquot of each cell culture by vital dye exclusion ( $0.4 \%$ trypan blue).

\section{Subjects}

The study population was comprised of 53 married women of reproductive age. All subjects had been tested for aerobic and anaerobic organisms within the past 12 months and treated if culture positive. All were tested for Chlamydia trachomatis by the Amplicor polymerase chain reaction (PCR; Roche Diagnostics, Branchberg, NJ) at the time of sample collection, and none were positive. At the time of the study, none of the women were using contraception.

\section{Cervical Sample Preparation}

Cervical samples were obtained from all women at mid-cycle by inserting a Dacron swab into the endocervix, twirling the swab, and then removing it into a tube containing $0.5 \mathrm{~mL}$ PBS. Samples were vortexed, and liquid was extracted from the swab using a sterile Pasteur pipette. Cells were pelleted by centrifugation and the supernatant removed and frozen at $-80^{\circ} \mathrm{C}$ until used for the determination of anti-Hsp70 antibodies. The cell pellet was washed three times with PBS, and RNA was immediately extracted as described below.

\section{RNA Isolation}

Cell pellets were resuspended in $0.2 \mathrm{~mL} 10-\mathrm{mM}$ Tris-HGl pH 7.5, containing $0.15 \mathrm{M} \mathrm{NaCl}, 1.5 \mathrm{mM}$ $\mathrm{MgCl}_{2}, 0.65 \%$ Nonidet P-40 detergent, and $1 \mu \mathrm{L}$ RNAguard ribonuclease inhibitor (Pharmacia, Piskataway, NJ), to lyse the cells and release the 
nucleic acid. Following centrifugation for $5 \mathrm{~min}$. at $6500 \mathrm{rpm}$, the supernatant was removed, admixed with an equal volume of $7 \mathrm{M}$ urea, $1 \%$ sodium dodecyl sulfate, $0.35 \mathrm{M} \mathrm{NaCl}, 10 \mathrm{mM}$ EDTA, and $10 \mathrm{mM}$ Tris-HCl. RNA was extracted by addition of an equal volume of 50:50:1 phenol:chloroform:isoamyl alcohol. The samples were vortexed and centrifuged at $12,500 \mathrm{rpm}$ for $4 \mathrm{~min}$. at $4^{\circ} \mathrm{C}$. The RNA underwent a double extraction procedure to ensure RNA purity. RNA was precipitated at $-20^{\circ} \mathrm{C}$ overnight in $100 \%$ ethanol and $3 \mathrm{M}$ sodium acetate, washed with $-20^{\circ} \mathrm{C} 70 \%$ ethanol, dried by desiccation, and resuspended in diethyl pyrocarbonate-treated water. Samples were stored at $-80^{\circ} \mathrm{C}$ until reverse transcription (RT) and PCR were performed.

\section{Deoxyribonuclease Treatment and Reverse Transcription of RNA}

Prior to RT of the RNA, samples were treated for 15 min. with 1 unit of amplification grade Deoxyribonuclease (DNase 1, Gibco BRL Life Technologies, Grand Island, NY) to destroy any contaminating DNA. DNase activity was removed by the addition of $2 \mathrm{mM}$ EDTA and heating for 10 $\min$. at $65^{\circ} \mathrm{C}$.

Reverse transcription of RNA to complementary DNA (cDNA) was performed in the presence of 60 units murine Maloney leukemia virus reverse transcriptase (Gibco BRL) in $50 \mathrm{mM}$ Tris- $\mathrm{HCl}, 75 \mathrm{mM}$ $\mathrm{KCl}, 3 \mathrm{mM} \mathrm{MgCl}{ }_{2}, 100 \mathrm{~g} / \mathrm{mL}$ bovine serum albumin, $0.5 \mathrm{mM}$ each dATP, dCTP, dGTP, and dTTP (Promega, Madison, WI), $1330 \mathrm{U} / \mathrm{mL}$ $\mathrm{RNasin}$ ribonuclease inhibitor (Promega) and 50 $\mu \mathrm{g} / \mathrm{mL}$ oligo $\mathrm{dT}_{15}$ primer. RNA samples were incubated for $60 \mathrm{~min}$. at $37^{\circ} \mathrm{C}$, heated at $95^{\circ} \mathrm{C}$ for 5 min. to inactivate the reverse transcriptase, and stored at $-80^{\circ} \mathrm{C}$ until PCR was performed.

\section{Polymerase Chain Reaction}

Aliquots of cDNA were combined with reaction buffer $\left(10 \mathrm{mM}\right.$ Tris-HCl, $1.5 \mathrm{mM} \mathrm{MgCl}_{2}, 50 \mathrm{mM}$ $\mathrm{KCl}, 200 \mu \mathrm{M}$ each of dATP, dCTP, and dGTP, and $190 \mu \mathrm{M}$ dTTP and $10 \mu \mathrm{M}$ digoxigenin-11-2'deoxyuridine-5' -triphosphate [dig-11-dUTP, Boehringer Mannheim, Indianapolis, IN]), 0.15 $\mu \mathrm{M}$ Hsp70 oligonucleotide primer pairs for the inducible Hsp70 (StressGen, Victoria, B.C., Canada), and 1.25 units of Taq DNA polymerase in a total volume of $50 \mu \mathrm{L}$. Samples were subjected to one cycle at $95^{\circ} \mathrm{C}$ for $3 \mathrm{~min}$., $48^{\circ} \mathrm{C}$ for $30 \mathrm{sec}$., $72^{\circ} \mathrm{C}$ for $1 \mathrm{~min}$., $30 \mathrm{sec}$. followed by 28 cycles of $95^{\circ} \mathrm{C}$ for $15 \mathrm{sec}$., $55^{\circ} \mathrm{C}$ for $30 \mathrm{sec}$, $72^{\circ} \mathrm{C}$ for $1 \mathrm{~min}$., $30 \mathrm{sec}$., followed by a $5 \mathrm{~min}$. extension cycle at $72^{\circ} \mathrm{C}$. The PCR products were subjected to electrophoresis on $1.7 \%$ agarose gels, stained with ethidium bromide, and visualized under ultraviolet light.

As a control to guarantee that cDNA synthesis occurred in our samples, each sample was examined for the presence of $\beta$-actin cDNA. Samples of cDNA were amplified, using the same reaction conditions as above, in the presence of 6 pmol of human $\beta$-actin specific primers: reverse 5'-CGT CAT ACT CGT GCT TGG TGA TCG AAT CTGC-3' and forward 5'-ATC TGG CAC CAC ACG TTC TAC AAT GAG CTG CG-3' (Oswel DNA Service, Southhampton, England).

\section{Quantitation of Amplified PCR Products by Enzyme-Linked Immunosorbent Assay}

Amplified PCR products were detected by enzyme-linked immunosorbent assay (ELISA) following hybridization with an Hsp70-specific internal probe, to increase sensitivity and specificity of mRNA detection from the human endocervicalderived samples. Aliquots $(10 \mu \mathrm{L})$ of digoxigeninamplified PCR products were denatured at $25^{\circ} \mathrm{C}$ for $10 \mathrm{~min}$. and hybridized with $7.5 \mathrm{pmol} / \mathrm{mL}$ of a biotinylated Hsp70-specific oligonucleotide probe: biotin 5'-GCA AGG TGG AGA TCA TCG CGA ACG ACG AGG-3' (Oswel DNA Service). Digoxigenin-labeled biotin PCR complexes were then incubated in a streptavidin-coated microtitre plate for $3 \mathrm{hr}$. at $51.1^{\circ} \mathrm{C}$, and the bound product was detected using peroxidase conjugated anti-digoxigenin antibody (Boehringer Mannheim) and the colorimetric substrate ABTS (2,2' -azino-di-[3ethylbenzthiazoline sulfate (6)] diammonium salt). Wells containing no cDNA and negative PCR amplification products were used as negative ELISA controls. Known concentrations of human DNA $(0.2-60 \mathrm{ng} / \mathrm{mL})$ were amplified by PCR to derive a standard curve.

\section{Detection of Immunoglobulin A Antibodies to Hsp70 in Cervical Supernatants}

Recombinant Hsp70 (StressGen) was diluted to 10 $\mu \mathrm{g} / \mathrm{mL}$ in $0.1 \mathrm{M}$ carbonate buffer, $\mathrm{pH} 9.8,0.1 \mathrm{~mL}$ added to wells of a microtitre plate, and the plate incubated at $4^{\circ} \mathrm{C}$ for $16 \mathrm{hr}$. The liquid was then 
TABLE I. Messenger RNA for Hsp70 in endocervical cells obtained at various times after sexual intercourse ${ }^{\mathrm{a}}$

\begin{tabular}{|c|c|c|c|c|c|c|}
\hline & \multicolumn{6}{|c|}{ Time since intercourse (hr) } \\
\hline & $<10$ & 10 & 11 & $12-16$ & $>48$ & Total \\
\hline No. of subjects & 8 & 14 & 10 & 11 & 10 & 53 \\
\hline No. positive (\%) & $3(37.5)$ & $9(64.3)$ & $7(70)$ & $4(36.4)$ & $5(50)$ & $28(52.8)$ \\
\hline Concentration $(\mathrm{ng} / \mathrm{ml})$ & $0.1-1.2$ & $0.2-7.9$ & $0.2-1.5$ & $0.2-1.9$ & $0.2-4.2$ & \\
\hline
\end{tabular}
$\mathrm{mL}$ PBS containing $0.5 \%$ Tween 20 detergent. Thawed cervical samples were diluted 1:5 in PBSTween and $0.1 \mathrm{~mL}$ added to individual wells. Following a $60-\mathrm{min}$. incubation in a $37^{\circ} \mathrm{C}$ water bath, the wells were washed three times as above, and $0.1 \mathrm{~mL}$ of a 1:500 dilution in PBS-Tween buffer of alkaline phosphatase (AP)-conjugated goat antibody to human immunoglobulin A (IgA; Kirkegaard and Perry, Gaithersburg, MD) was added to the wells. After an additional $60 \mathrm{~min}$. at $37^{\circ} \mathrm{C}$, the wells were again washed three times and the AP substrate, p-nitrophenylphosphate in $10 \%$ diethanolamine buffer, pH 9.8, was added. The development of a yellow color in the wells was quantitated at $405 \mathrm{~nm}$ after $30 \mathrm{~min}$. with a microtitre plate reader. Known positive and negative samples were always tested in parallel to the test samples. A sample was considered positive for IgA antibodies to Hsp70 if the final absorbance was at least two standard deviations above the mean absorbance value obtained with cervical samples from 25 healthy reproductive-age female controls not exposed to semen for more than 7 days (a value $\geq$ $0.227)$.

\section{Hsp70 mRNA from HeLa cells was examined. At} three different concentrations, filter-sterilized seminal fluid induced Hsp70 mRNA. No Hsp70 mRNA was detected in HeLa cultures in the absence of seminal fluid or from seminal fluid alone. The lack of a dose response in Hsp70 mRNA induction was probably a result of seminal fluid cytotoxicity on HeLa cells at the higher concentrations. The cell viability of HeLa cell cultures with a 1:50 dilution of semen, seminal fluid, or motile sperm was more than $90 \%$.

HeLa cells cultured with motile sperm at a HeLa:sperm ratio of $1: 10$ or $1: 2$ resulted in induction of Hsp70 mRNA. Heat shock protein 70-specific mRNA was not detected in HeLa cultures in the absence of sperm or from cultures of motile sperm that contained no HeLa cells.

\section{Induction of Hsp70 mRNA in Endocervical Cells Following Sexual Intercourse}

Endocervical cells obtained from women at different times after sexual intercourse were examined for Hsp70 mRNA by RT-PCR ELISA. The Hsp70 mRNA was detected in $28(52.8 \%)$ of 53 samples that were positive for $\beta$-actin RNA. The relation between time since exposure to semen and the prevalence and concentration of $\mathrm{Hsp} 70 \mathrm{mRNA}$ is shown in Table 1. Among women exposed to semen less than 10 hours prior to sample collection, $37.5 \%$ had endocervical Hsp70 mRNA. This percentage increased to $64.3 \%$ at 10 hours after intercourse, $70 \%$ at 11 hours after intercourse, and decreased to $40-50 \%$ at longer time intervals (Table 1 ).

\section{Induction of IgA Antibodies to Hsp70 in the Endocervix Following Sexual Intercourse}

tected in semen alone or in HeLa cells incubated in the absence of semen. Equivalent concentrations of $\beta$-actin mRNA were detected in all HeLa cell cultures but not in semen or semen components

The ability of cell-free seminal fluid and motile

The supernatant fraction of endocervical swab material, available from 36 of the subjects, was examined for IgA antibodies to the human Hsp70. Samples from 10 women $(27.8 \%)$ were positive. 
TABLE 2. Induction of cervical IgA antibodies to Hsp70 and relation to mRNA induction

\begin{tabular}{lcc}
\hline $\begin{array}{l}\text { No. with IgA } \\
\text { anti-Hsp70 (\%) }\end{array}$ & No. of samples & Hsp70 mRNA \\
\hline $8(80)$ & 10 & Positive \\
$2(7.7)$ & 27 & Negative \\
\hline
\end{tabular}

$P=0.0001$ (Fisher exact test).

The presence of cervical anti-Hsp70 IgA correlated with detection of cervical Hsp70 mRNA $(P<$ $0.0001)$; this antibody was present in eight $(80 \%)$ of 10 women with detectable Hsp70 mRNA and in only two $(7.7 \%)$ of 26 women without detectable Hsp70 mRNA (Table 2). The prevalence of IgA antibodies to Hsp70 increased with the time since last semen exposure $(P=0.008)$. Immunoglobulin A anti-Hsp70 was identified in the cervices of five $(71.4 \%)$ of seven women who had sexual intercourse greater than 48 hours prior to sample collection, in four $(17.4 \%)$ of 23 women exposed to semen from 10 to 16 hours earlier, and in one (12.5\%) of eight women who had intercourse less than 10 hours before sample collection (Table 3). An increased production of antibodies in women previously sensitized to Hsp70 following re-exposure to newly synthesized Hsp70 protein after intercourse is consistent with the induction of a secondary immune response.

\section{DISCUSSION}

Hsp 70 gene transcription was induced in vivo and in vitro in endocervix-derived cells following exposure to semen. Cell-free seminal fluid and motile sperm were also capable of initiating this response. The cells that actually produce Hsp70 mRNA have not yet been identified.

The presence of Hsp70 has been identified in human sperm and seminal fluid. However, in all our experiments, all nonadherent semen components were removed by washing, and we were unable to detect Hsp70 mRNA in spermatozoa. Therefore, we are confident that the source of Hsp70 was the HeLa cells. Identification of Hsp70 mRNA in cervical cells obtained from women after sexual intercourse parallels the in vitro observations with cultured cells. The correlation between Hsp70 mRNA and cervical IgA antibodies to Hsp70 in cervical cells following exposure to semen further suggests that Hsp70 gene transcription
TABLE 3. Presence of $\lg A$ antibodies to Hsp70 versus time since semen exposure

\begin{tabular}{lccc}
\hline & \multicolumn{3}{c}{$\begin{array}{c}\text { Time since } \\
\text { intercourse (hr) }\end{array}$} \\
\cline { 2 - 5 } & $>48$ & $10-16$ & $<10$ \\
\hline No. of women with anti-Hsp70 & & & \\
IgA present (\%) & $5(71.4)$ & $4(17.4)$ & $1(12.5)$ \\
Total no. of women & 7 & 23 & 8 \\
\hline$P=0.008$. & & & \\
\end{tabular}

and the subsequent production of Hsp70 protein stimulated a localized immune response.

There is a possibility that the Hsp70 in semen could have contributed to the cervical anti-Hsp70 IgA response. However, none of the semen samples used in the HeLa cell experiments contained Hsp70 mRNA. Notwithstanding, the semen samples from the male partners of the women in our study were not available and, therefore, were not assayed for Hsp70 protein.

Heat shock proteins accumulate within virally infected cells and appear to play a significant role in some viral infections. Hsp 70 specifically is intimately associated with the life cycles of numerous RNA and DNA viruses. Hsp 70 may be required to promote the transcription of viral genes, assembly of viral polypeptides, and/or virus infectivity. 9,10 During vaccinia infection, Hsp70 mRNA directly associates with intracellular vaccinia proteins and may act as a chaperonin in the assembly of this virus. ${ }^{11}$ Induction of Hsps by elevated temperature upregulates virus production from cell lines chronically infected with human immunodeficiency virus (HIV). ${ }^{12}$ Hsp induction by heat or chemicals activated the long terminal repeat (LTR) of HIV. In HeLa cells transfected with the HIV-1 LTR, Hsp induction by heat induced the transcription of the HIV-1 LTR and the Hsp70 heat shock promoter. ${ }^{13}$ Elevations in HIV reverse transcriptase were observed for 72 hours following heat shock in infected lymphocytic and monocytic cell lines. Cells allowed to recover after heat shock first showed a lag in release of viral particles, followed by accelerated viral release in stressed cells. Physiological levels of heat shock were not able to induce virus production from cells in vitro. However, these temperatures were able to act synergistically with interleukin-6 and granulocyte macrophage-colony stimulating factor to enhance virus production. ${ }^{13}$ Viral activation in response to environmental stress has 
also been identified for cytomegalovirus (CMV). ${ }^{14}$ A DNA sequence present in the enhancer element of CMV, similar to a decameric sequence in the $\mathrm{NF}-\mathrm{kB}$ binding site of the HIV LTR, resembled the heat shock element core consensus regulatory sequence. ${ }^{14,15}$ This suggested that either Hsps may activate CMV genes or that Hsp genes and CMV genes respond to similar stimuli. Initiation of Hsp70 transcription thus might facilitate the reactivation of latent viral infections, as well as augment viral replication and transmission from an infected donor to a noninfected recipient by promoting enhanced viral production.

Since viruses such as HIV and CMV are sexually transmitted, it was of interest to determine whether semen and its components could activate Hsp transcription in cervical cells. Such expression might facilitate the reactivation of latent viral infections as well as augment viral transmission from an infected donor to a noninfected recipient.

Whether semen-induced Hsp70 is beneficial in inhibiting immune responses to spermatozoa, harmful in facilitating viral infectivity, or inhibits immune activation in response to other sexually transmitted infections may depend on a number of factors. The capacity of individual women's cells to transcribe, translate, and degrade Hsp70 mRNA is under genetic control. In addition, the components of individual semen samples to induce $\mathrm{Hsp} 70 \mathrm{ex}$ pression may differ. The presence of virally infected cells or microbial pathogens in the female genital tract or in the ejaculate may influence the consequences of Hsp70 transcription. The observed difference between women at various times after intercourse may be related to these factors.

The effect of semen on Hsp70 transcription in additional epithelial and nonepithelial cell lines is currently under investigation. The effect of sexual intercourse on cytokine expression and whether Hsp70 expression differs in women using various forms of birth control is also being explored.

\section{REFERENCES}

1. Burel C, Mezger V, Pinto M, et al. Mammalian heat shock protein families. Expression and functions. Experientia 1992;48:629-634.

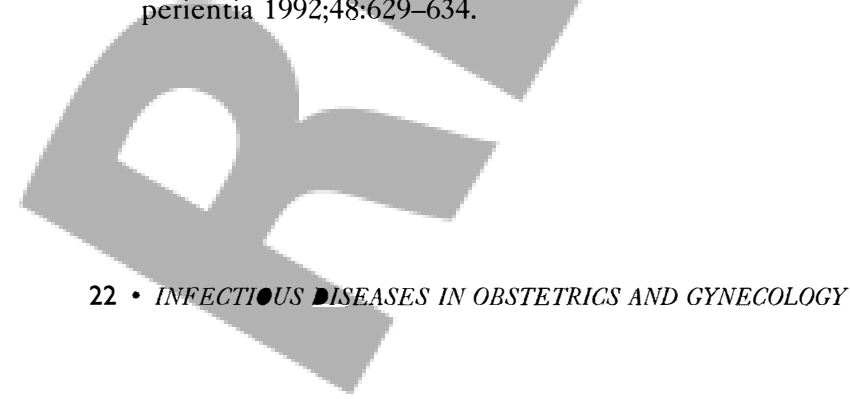

2. Kantengwa S, Donati YRA, Clergot M, et al. Heat shock proteins: an autoprotective mechanism for inflammatory cells? Semin Immunol 1991;3:49-56.

3. Schmidt JA, Abdulla E. Down regulation of IL-1 biosynthesis by inducers of the heat shock response. J Immunol 1988;141:2027-2034.

4. Snyder YM, Guthrie L, Evans GF, Zuckerman SH. Transcriptional inhibition of endotoxin-induced monokine synthesis following heat shock in murine peritoneal macrophages. J Leukoc Biol 1992;51:181-187.

5. Hall TJ. Role of HSP70 in cytokine production. Experientia 1994;50:1048-1053.

6. Cahill MC, Waterman WR, Xie Y. Transcriptional repression of the prointerleukin 1 gene by heat shock factor. J Biol Chem 1996;271:24874-24879.

7. Bendich A, Borenfreund E, Sternberg SS. Penetration of somatic mammalian cells by sperm. Science 1974;183: 857-859.

8. Hang H, Fox MH. Low pH suppresses synthesis of heat-shock proteins and thermotolerance. Radiat Res 1994;140:24-30.

9. La Thangue B, Shriver K, Dawson C, Chan WL. Herpes simplex virus infection causes the accumulation of heat shock protein. EMBO J 1984;3:267-277.

10. Santoro MG. Heat shock proteins and virus replication: HSP70s as mediators of the antiviral effects of prostaglandins. Experientia 1994;50:1048-1053.

11. Chouchane L, Bowers FS, Sawasdikosol S, Simpson RM, Kindt TJ. Heat shock proteins expressed on the surface of human $\mathrm{T}$ cell leukemia virus type 1 -infected cell lines induce autoantibodies in rabbits. J Infect Dis 1994;169:253-259.

12. Stanley SK, Bressler PB, Poli G, Fauci AS. Heat shock induction of HIV production from chronically infected promonocytic and T cell lines. J Immunol 1990;145: 1120-1126.

13. Geelan JLMC, Minnaar PR, Boom R, van der Noorda J, Goudsmit J. Heat shock induction of the human immunodeficiency virus long terminal repeat. J Gen Virøl 1988;69:2913-2917.

14. Geelan JLMC, Boom R, Klaver PM, et al. Transcriptional activation of the major immediate early transcription unit of cytomegalovirus by heat shock, arsenite, and protein synthesis inhibitors. J Gen Virol 1987;68:29252931.

15. Hagemeier C, Walker SM, Sissons PJ, Sinclair JH. The 72k IE 1 and $80 \mathrm{~K}$ IE2 proteins of human cytomegalovirus independently trans-activate the c-fos, c-myc, and HSP70 promoters via basal promoter elements. J Gen Virol 1992;73:2385-2393. 